\title{
Nonlinear growth dynamics of date palms responding to environmental parameters
}

\author{
1,* Magero, E.J., ${ }^{1}$ Unami, K., ${ }^{2}$ Mohawesh, O., ${ }^{1}$ Yamaguchi, M. and ${ }^{1}$ Fujihara, M. \\ ${ }^{1}$ Graduate School of Agriculture, Kyoto University, Kitashirakawa-oiwake-cho, Sakyo-ku, Kyoto 606-8281, \\ Japan. \\ ${ }^{2}$ Faculty of Agriculture, Mutah University, P.O. Box 7, Karak, Jordan.
}

\section{Article history:}

Received: 1 April 2020

Received in revised form: 18

August 2020

Accepted: 22 August 2020

Available Online: 27

December 2020

Keywords:

Date palm,

Dendrometer,

Drip irrigation,

Nonlinear dynamics,

Volterra series

DOI:

https://doi.org/10.26656/fr.2017.4(S6).009

\begin{abstract}
Scientific analysis of plant growth helps in improving the efficiency of cultivation practices through optimization of their environmental conditions. The ultimate aim of this research was to derive an optimal policy for better growth of date palms by considering its dynamical response to environmental parameters such as solar radiation, soil moisture, and temperature. Field experiments were conducted at an irrigation scheme located in the Jordan Rift Valley. A drip irrigation system is installed to water ten trees of date palms either with fresh or saline water depending on the soil matric potential. The circumference of the trunk of a tree was measured using a dendrometer at 30 mins interval and recorded in a data logger. Environmental parameters including the soil matric potential, solar radiation, and soil temperature were also logged every 30 mins. This study focused on determining a nonlinear model representing the growth dynamics of the date palm tree responding to those environmental parameters. The linear regression was applied to estimate the kernel coefficients of discrete Volterra series modeling the time series. The non-linearity of the model is expected to explain diurnal shrinkage and swelling of the tree trunk under different environmental conditions.
\end{abstract}

\section{Introduction}

The level of crop production is highly dependent on the efficiency of cultivation practices through optimization of their environmental conditions. Over the years, a plethora of studies on plant growth analysis have been conducted and proven to sufficiently contribute to development of better agronomic practices. Deriving an optimal policy will thus contribute to improved management in crop production by providing an insight on how to tailor environmental parameters to favour possible better growth response and eventually lead to higher yields.

Modeling of dynamic systems aids in revealing information from complex relationships which have not been detected using traditional analysis and designs. Likewise, it can be used to analyze experiments that involve collection of repetitive measurements, over time, which cannot be well represented using simpler methods such as factorial analysis of variance (Wang et al., 2015; Irwin and Wang 2017).

This study involves field experiments that are conducted at an irrigation scheme located in the Jordan Rift Valley, where the climate is extremely arid with soils of high salinity levels according to Unami et al. (2015). It has a reservoir equipped with facilities for flash floods harvesting (Unami and Mohawesh, 2018) and is fitted with a desalination plant used to provide fresh water (Unami et al., 2019). A drip irrigation system is installed to water 10 trees of date palms either with fresh or saline water depending on the soil matric potential monitored every few days using a tensiometer. The circumference of the trunk is used as an indicator of the growth of a tree, measured using a dendrometer with a 30 mins interval $(\Delta t)$ and recorded in a data logger. Different environmental parameters are monitored at the site.

It is known that the change in circumference increment of the tree trunk over time had diurnal shrinkage and swelling under different environmental conditions (Ueda and Shibata 2002). Volterra series was thus applied to represent the nonlinearity of the growth dynamics, and different environmental conditions are hypothesized to dominate the kernel coefficients as the response of the plant. Therefore, the aim of this research 
was to test this hypothesis by examining the kernel coefficients estimated from the observed data.

\section{Materials and methods}

\subsection{Experimental setup}

The circumference of the trunk of one of the date palm trees is measured using a dendrometer Ecomatic $\mathrm{DC} 2$ at 30 mins interval $(\Delta t)$ and recorded in a data logger HOBO U12. Environmental parameters including the soil matric potential, solar radiation, and soil temperature are also logged every 30 mins, using a mol ML-2400AEL tensiometer, a Hukseflux SR05 pyranometer, and a METER 5TE soil sensor, respectively. Figure 1 shows the date palm tree with the drip tubes, the dendrometer, the data loggers, and the pyranometer.

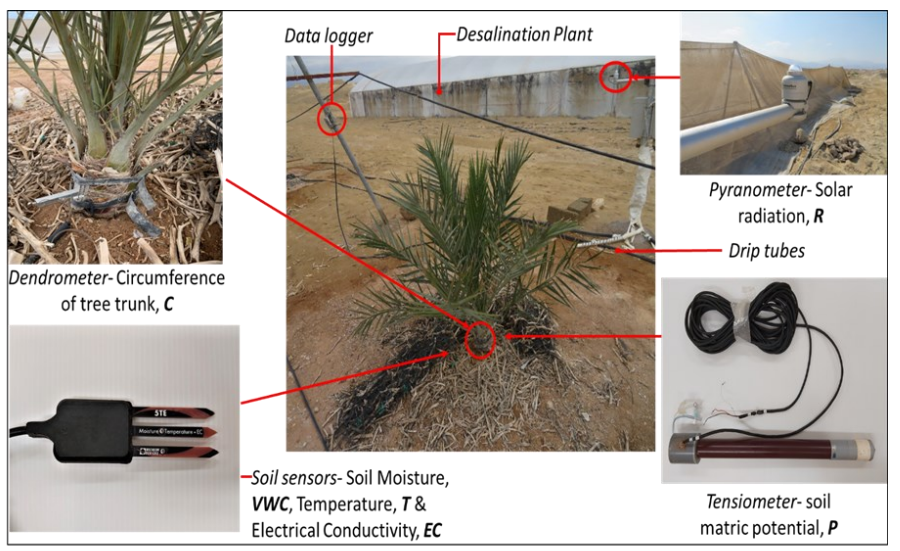

Figure 1. Experimental site of irrigated date palms including instruments and sensors for measuring their respective environmental parameters.

\subsection{Mathematical methods}

A discrete Volterra series of order 1 is used for representing the growth dynamics as:

$$
C_{t+1}=a_{0}+a_{1} C_{t}+a_{2} C_{t}^{2}+\varepsilon_{t}
$$

where $C_{t}(\mathrm{dm})$ is the circumference of the tree trunk at time $t \Delta t, a_{i}(\mathrm{i}=0,1,2)$ are the kernel coefficients, and $\varepsilon_{t}$ represents the error. The kernel coefficients are assumed to vary in response to the different environmental parameters. The least squares method is used to estimate the value of the kernel coefficients that are the best fit to a set of data for certain ranges of the environmental parameters. The resultant simultaneous equations are represented as:

$$
\left(\begin{array}{ccc}
\sum 1 & \sum C_{t} & \sum C_{t}^{2} \\
\sum C_{t} & \sum C_{t}^{2} & \sum C_{t}^{3} \\
\sum C_{t}^{2} & \sum C_{t}^{3} & \sum C_{t}^{4}
\end{array}\right)\left(\begin{array}{l}
a_{0} \\
a_{1} \\
a_{2}
\end{array}\right)=\left(\begin{array}{c}
\sum C_{t+1} \\
\sum C_{t} C_{t+1} \\
\sum C_{t}^{2} C_{t+1}
\end{array}\right)
$$

which is solved with the Gauss-Seidel method in order to estimate the kernel coefficients for each combination of ranges of the environmental parameters.
A total of six variables were selected as the environmental parameters dominating the kernel coefficients: the solar radiation $R\left(\mathrm{~W} / \mathrm{m}^{2}\right)$; the soil matric potential $P\left(\log _{10} \mid\right.$ Value in $\left.\mathrm{kPa} \mid\right)$, the soil temperature $T$ $\left({ }^{\circ} \mathrm{C}\right)$; and their increment in $\Delta t$ which are denoted by $\Delta R$, $\Delta P$, and $\Delta T$ respectively. The kernel coefficients estimated from different combinations of ranges of the environmental parameters are modelled with the linear regression formulas

$a_{i}=\alpha_{i 0}+\alpha_{i 1} R+\alpha_{i 2} P+\alpha_{i 3} T+\alpha_{i 4} \Delta R+\alpha_{i 5} \Delta P+\alpha_{i 6} \Delta T$

where $\alpha_{i j}(j=0,1, \ldots 6)$ are the coefficients identified with the least square method.

\subsection{Acquired data}

We finally obtained four sets of data series during the periods from August $3^{\text {rd }}, 2018$ through September $27^{\text {th }}, 2018$ (Period A), from October 22 $2^{\text {nd }}, 2018$ through December $27^{\text {th }}, 2018$ (Period B), from February $11^{\text {th }}$, 2019 through April 27 ${ }^{\text {th }}, 2019$ (Period C), and from November 22 2019 through November $29^{\text {th }}, 2019$ (Period D).

\section{Results}

\subsection{Partitioning ranges of the environmental parameters}

The samples of each environmental parameter are sorted and divided into groups of almost identical populations to determine the ranges. After a process of trial and error, the numbers of groups are decided as 3 for $R, 5$ for $P, 1$ for $T, 3$ for $\Delta R, 3$ for $\Delta P$, and 2 for $\Delta T$ making the 270 combinations of the ranges.

\subsection{Linear regression formulas for the kernel coefficients}

The identification results for the coefficients $\alpha_{i j}$ defined in (3) are summarized in Tables 1 to 4. These values can be considered as the sensitivity of the kernel coefficients to the environmental parameters.

\section{Discussion}

Figure 2 is used as an example to illustrate the diurnal shrinkage and swelling of the circumference of the tree trunk in comparison with the estimated one. The observed values of the circumference generally ranged between 2.98 and 4.61, implying that the $\alpha_{2 j}$-values are not negligible and that the quadratic terms of the Volterra series have significant effects on the growth dynamics. The diurnal shrinkage and swelling of the tree trunk may be driven by the solar radiation and the soil temperature, as the corresponding $\alpha_{i j}(j=1,3,4,6)$ have significant values. However, the signs of most $\alpha_{i j}$ are indefinite, and the response to the soil moisture in particular, which instantaneously increases when 
Table 1. Identified coefficients $\alpha_{i j}$ for the period A

\begin{tabular}{lccccccc}
\hline & $j=0$ & $j=1$ & $j=2$ & $j=3$ & $j=4$ & $j=5$ & $j=6$ \\
$i=0$ & 0.191 & 0.00028 & 0.318 & -0.0134 & 0.00151 & -0.457 & -0.459 \\
$i=1$ & 0.885 & -0.000165 & -0.184 & 0.0078 & -0.000899 & 0.542 & 0.505 \\
$i=2$ & 0.0102 & 0.0000101 & -0.00119 & -0.000163 & 0.0000548 & -0.542 & -0.376 \\
\hline
\end{tabular}

Table 2. Identified coefficients $\alpha_{i j}$ for the period B

\begin{tabular}{cccccccc}
\hline & $j=0$ & $j=1$ & $j=2$ & $j=3$ & $j=4$ & $j=5$ & $j=6$ \\
$i=0$ & 0.667 & -0.000586 & 0.744 & -0.0274 & -0.00102 & -0.0701 & -1.79 \\
$i=1$ & 0.613 & 0.000336 & -0.429 & 0.0160 & 0.000542 & 0.0669 & 1.10 \\
$i=2$ & 0.0565 & -0.0000490 & 0.0603 & -0.00227 & -0.0000753 & -0.0496 & -0.183 \\
\hline
\end{tabular}

Table 3. Identified coefficients $\alpha_{i j}$ for the period C

\begin{tabular}{cccccccc} 
& $j=0$ & $j=1$ & $j=2$ & $j=3$ & $j=4$ & $j=5$ & $j=6$ \\
$i=0$ & 1.47 & 0.000219 & 0.355 & -0.0267 & 0.0000700 & -0.622 & 0.166 \\
$i=1$ & 0.345 & 0.0000333 & 0.0364 & -0.00327 & 0.00000501 & -0.279 & -0.0235 \\
$i=2$ & 0.0826 & 0.00000688 & 0.00632 & -0.000633 & -0.00000886 & -0.241 & -0.0248 \\
\hline
\end{tabular}

Table 4. Identified coefficients $\alpha_{i j}$ for the period D

\begin{tabular}{lccccccc}
\hline & $j=0$ & $j=1$ & $j=2$ & $j=3$ & $j=4$ & $j=5$ & $j=6$ \\
$i=0$ & 2.20 & 0.00114 & 0.573 & -0.0435 & -0.00401 & 0.213 & -0.474 \\
$i=1$ & 0.266 & -0.000113 & -0.0559 & 0.00425 & 0.000485 & 0.199 & 0.324 \\
$i=2$ & 0.0613 & -0.0000178 & -0.00802 & 0.000638 & 0.000121 & 0.181 & 0.170 \\
\hline
\end{tabular}

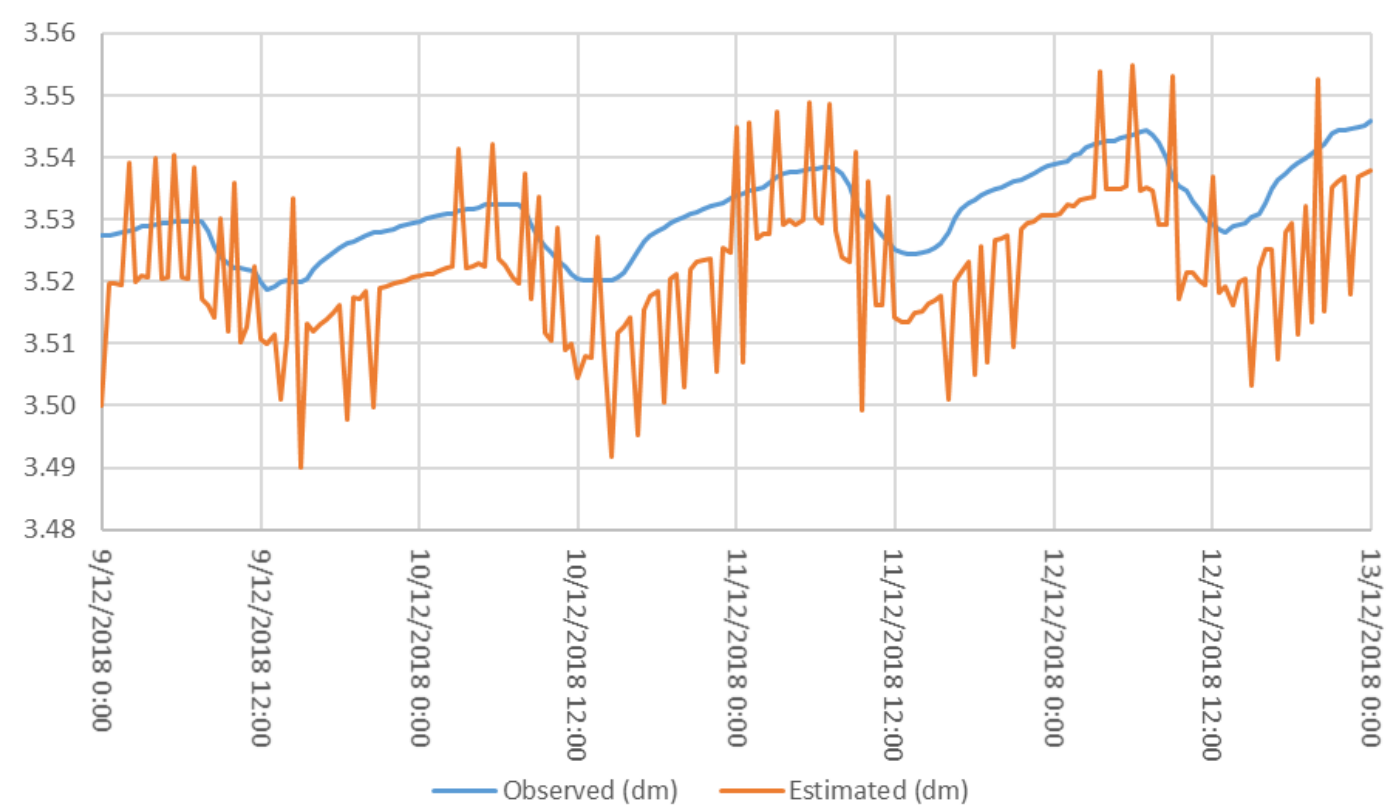

Figure 2. Observed and estimated changes in the circumference of the tree trunk from 0:00 on December $9^{\text {th }}$, 2018 to 0:00 on December $13^{\text {th }}, 2018$ (Irrigation was performed with saline water during 11:30-13:30 on December 10 ${ }^{\text {th }}, 2018$ ).

irrigated, is not well quantitated. It is inferred that the structure of the model, which is of order 1 , is not the best to represent hysteresis which is intrinsic to plant growth and dynamics of soil moisture. The models of higher orders shall be considered in the follow up studies.

\section{Conclusion}

Modelling the growth dynamics of date palms with the Volterra series revealed its nonlinearity and response to diurnal behaviours of the environmental parameters. However, the relationship between the plant physiology and the soil moisture is still unclear. The model should be improved to achieve the goal of higher yields of agricultural products.

\section{Acknowledgement}

This research is funded by Grants-in-Aid for Scientific Research No. 16KT0018 and No.19KK0167 from the Japan Society for the Promotion of Science (JSPS).

\section{References}

Irwin, M. and Wang, Z. (2017). Dynamic Systems Modeling. In Matthes, J., Davis, C.S. and Potter, R.F. (Eds). The International Encyclopedia of Communication Research Methods, p. 1-12. 
Hoboken, New Jersey, USA: John Wiley \& Sons, Inc. $\quad$ https://

doi.org/10.1002/9781118901731.iecrm0074

Ueda, M. and Shibata, E. (2002). Water status of Hinoki cypress (Chamaecyparis obtusa) under reduced hydraulic conductance estimated from diurnal changes in trunk diameter. Trees-Structure and Function, 16, 523-528. https://doi.org/10.1007/ s00468-002-0196-0

Unami, K. and Mohawesh, O. (2018). A unique value function for an optimal control problem of irrigation water intake from a reservoir harvesting flash floods. Stochastic Environmental Research and Risk Assessment, 32, 3169-3182. https://doi.org/10.1007/ s00477-018-1527-z

Unami, K., Mohawesh, O. and Fujihara, M. (2020). Prototype and model of solar driven desalination plant in arid environment. Thermal Science, 24(2), 903-914. https://doi.org/10.2298/TSCI180604097U

Unami, K., Mohawesh, O., Sharifi, E., Takeuchi, J. and Fujihara, M. (2015). Stochastic modelling and control of rainwater harvesting systems for irrigation during dry spells. Journal of Cleaner Production, 88, 185-195.

https://doi.org/10.1016/ j.jclepro.2014.03.100

Wang, Z., Vang, M., Lookadoo, K., Tchernev, J.M. and Cooper, C. (2015). Engaging high-sensation seekers: the dynamic interplay of sensation seeking, message visual-auditory complexity and arousing content. Journal of Communication, 65(1), 101-124. https:// doi.org/10.1111/jcom. 12136 